UDC 811.581

\title{
THE THEORY OF THE RELATION OF THE CONCEPTS OF "TEXT" AND "DAO", AND ITS INFLUENCE ON THE DEVELOPMENT OF TEXT SCIENCE IN ANCIENT CHINA
}

\author{
Zhao Zhonggang \\ Dr. in Philology, Researcher \\ School of Foreign Languages of Capital Normal University \\ 105, Xisanhuanbeilu str., Beijing, 100048, China \\ zhaozhonggang1991@163.com
}

This article examines the relationship between the concepts of "text" and "Dao". These two concepts are important for such scientific fields of ancient China as literary theory, philosophy, text science and others, and the relationship between them is interpreted differently depending on a number of factors. The first part of this article examines the interpretation of the concepts of "text" and "Dao" in different dynasties. First, in the Zhou Dynasty (1045-221 B.C.) the concept of "text" denotes an interlacing of multicolored patterns, from which follows the interpretation of text as beauty, bright color. Only in the Han dynasty (206 B.C. -220 A.D.) did the text begin to be understood as a completed work of speech in written form. The concept of "Dao" is a more complex and fuzzy concept that includes material, moral, spiritual-psychological and other components. The interpretation of the concept of "Dao" depends on such factors as one's ideological position and the political system of a particular time. The following is an analysis of the main trends in the development of the relationship between the two key concepts. The relationship between the concepts of "text" and "Dao" went from fusion to divergence and again to fusion and equilibrium. The fusion of the two concepts in the era before the Qin Dynasty (221-206 B.C.) is closely related to Confucianism, and the divergence of these concepts during the Southern and Northern Dynasties (420-589) is due to the dominance of the pair style. The two concepts came together again as a result of scholars' desire for a balance between content and form. The analysis summarizes the main characteristics of the relationship between the concepts of "text" and "Dao": multidimensionality, balance, harmony and ethicocentrism. The last part of the article is devoted to the analysis of the influence of the relationship between "text" and "Dao" on the development of textual studies in Ancient China, the science of ontological features of the text, which originated in the period of the Eastern Han dynasty (206-220). The discussion of the relationship between the concepts of "text" and "Dao" prior to the Qin dynasty contributes to the unification of disparate theoretical points regarding the understanding of textual patterns. In addition, the relationship between these two concepts also influences the genre diversity and expansion of textual issues in different periods.

Keywords: correlation, text, Dao, Confucianism, text science, genre.

(C) 2021 Zhao Zhonggang; Published by the A. Yu. Krymskyi Institute of Oriental Studies, NAS of Ukraine and the Ukrainian Association of Sinologists on behalf of The Chinese Studies. This is an Open Access article distributed under the terms of the Creative Commons Attribution License (https://creativecommons.org/licenses/by-nc-nd/4.0/). 


\title{
ТЕОРІЯ СПІВВІДНОШЕННЯ ПОНЯТЬ «ТЕКСТ» І «ДАО», ТА ЇЇ ВПЛИВ НА РОЗВИТОК ДАВНЬОКИТАЙСЬКОГО ТЕКСТОЗНАВСТВА
}

\author{
Чжао Чжунтан
}

У цій статті розглядається питання співвідношення понять «текст» і «Дао». Ці два поняття важливі в таких наукових галузях Стародавнього Китаю, як теорія літератури, філософія, текстознавство та інші, й співвідношення між ними по-різному інтерпретується в різні часи залежно від низки факторів. У першій частині статті розглядається інтерпретація понять «текст» $\mathrm{i}$ «Дао» в різних династіях. Спочатку в династії Чжоу (1045-221 pp. до н. е.) поняття «текст» позначає переплетення різнокольорових візерунків, з нього випливає наступна інтерпретація тексту як краса, яскравий колір. Тільки за часів династії Хань (206 р. до н. е. -220 р. н. е.) під текстом стали розуміти завершений у письмовій формі мовленнєвий твір. «Дао» являє собою більш складне і розмите поняття, що включає у себе матеріальний, моральний, духовно-психологічний та інші компоненти. Інтерпретація поняття «Дао» залежить від ідеологічної позиції людини і політичного, культурного, морально-етичного ладу того чи іншого часу. Далі аналізуються основні тенденції розвитку співвідношення двох ключових понять. Співвідношення понять «текст» і «Дао» пройшло шлях від злиття до розбіжності і знову до злиття і рівноваги. Злиття двох понять в епоху до династії Цінь (221-206 pp. до н. е.) було тісно пов'язане з конфуціанством, а розбіжність цих понять у період Південних і Північних династій (420-589 рр.) зумовлена домінуванням парного стилю. Ці два поняття знову злилися разом у результаті прагнення вчених до рівноваги між змістом і формою. На основі проведеного аналізу узагальнені основні характеристики співвідношення понять «текст» і «Дао»: багатовимірність, рівновага, гармонійність i етикоцентризм. Остання частина статті присвячена аналізу впливу співвідношення понять «текст» $\mathrm{i}$ «Дао» на розвиток давньокитайського текстознавства, науки про онтологічні особливості тексту, що бере свій початок у часи династії Східної Хань (206-220 рр.). Дискусії про співвідношення понять «текст» і «Дао» до династії Цінь сприяють об'єднанню розрізнених теоретичних учень стосовно розуміння закономірностей тексту. Крім того, співвідношення цих двох понять впливає і на жанрове різноманіття і розширення проблематики тексту в різні періоди.

Ключові слова: співвідношення, текст, Дао, конфуціанство, текстознавство, жанр.

\section{ТЕОРИЯ СООТНОШЕНИЯ ПОНЯТИЙ «ТЕКСТ» И «ДАО», И ЕЕ ВЛИЯНИЕ НА РАЗВИТИЕ ДРЕВНЕКИТАЙСКОГО ТЕКСТОВЕДЕНИЯ}

\section{Чжао Чжунган}

В данной статье рассматривается вопрос о соотношении понятий «текст» и «Дао». Эти два понятия важны для таких научных областей древнего Китая, как литературная теория, философия, текстоведение и другие, а соотношения между ними по-разному интерпретируется в зависимости от ряда факторов. В первой части статьи рассматривается интерпретация понятий «текст» и «Дао» в разных династиях. Сначала в династии Чжоу (1045-221 гг. до н. э.) понятие «текст» обозначает переплетение разноцветных узоров, из него вытекает следующая интерпретация текста как красота, яркий цвет. Только в династии Хань (206 г. до н. э. - 220 г.) под текстом стали понимать завершенное речевое произведение в письменной форме. Понятие «Дао» является более сложным и размытым понятием, которое включает в себя материальный, моральный, духовнопсихологический и другие компоненты. Интерпретация понятия «Дао» зависит от та- 
ких факторов, как идеологическая позиция человека и политический строй того или иного времени. Далее анализируются основные тенденции развития соотношения двух ключевых понятий. Соотношение между понятиями «текст» и «Дао» прошло путь от слияния до расхождения и снова до слияния и равновесия. Слияние двух понятий в эпоху до династии Цинь (221-206 гг. до н. э.) тесно связано с конфуцианством, а расхождение этих понятий в период Южных и Северных династий (420-589 гг.) обусловлено доминированием парного стиля. Эти два понятия снова соединились вместе в результате стремления ученых к равновесию между содержанием и формой. На основе проведенного анализа обобщены основные характеристики соотношения понятий «текст» и «Дао»: многомерность, равновесие, гармоничность и этикоцентризм. Последняя часть статьи посвящена анализу влияния соотношения «текст» и «Дао» на развитие древнекитайского текстоведения - науки об онтологических особенностях текста, которое берет свое начало в период династии Восточная Хань (206-220 гг.). Дискуссия о соотношении между понятиями «текст» и «Дао» до династии Цинь способствует объединению разрозненных теоретических моментов в отношении понимания закономерностей текста. Кроме того, соотношение этих двух понятий оказывает влияние и на жанровое разнообразие и расширение проблематики текста в разные периоды.

Ключевые слова: соотношение, текст, Дао, конфуцианство, текстоведение, жанр.

Вопрос о соотношении понятий «текст» и «Дао» представляет собой одну из центральных тем в древнекитайской литературной теории. Возникновение данного вопроса восходит к эпохе до династии Цинь, и по мере исторического развития он подвергается трансформации в результате непрерывной научной дискуссии. Такая дискуссия была обусловлена, во-первых, политическими, общественно-экономическими, культурными и другими обстоятельствами той или иной эпохи, в которую жили ученые; во-вторых, разногласием ученых в восприятии понятий «текст» и «Дао»; и в-третьих, научными и политическими идеями ученых разных времен. Изучение соотношения двух ключевых понятий углубляет понимание литературной теории той или иной эпохи и способствует исследованию в области древнекитайского текстоведения.

О понятиях «текст» и «Дао»

Прежде чем перейти к основному вопросу данной статьи, необходимо рассмотреть сами понятия «текст» и «Дао». Понятие «текст» (или, согласно другой терминологии, «литература») появилось в период Восточной Чжоу, но понималось и интерпретировалось по-разному. Так, в книге «Ши цзин» под текстом понимаются нормы этикета и музыки. В данный период встречается сочетание слов «текст» и «норма» (ганизи вэньчжан). Затем в период Воюющих царств текст интерпретировали как разнообразие ярких цветов. Об этом говорил Жэнь Суйху «Текстом (вэньчжсан), как зафиксировано в книге «Чжоу ли», называется переплетение узоров черного, красного и белого цветов» [任 遂虎 2011,1$]$. Такую точку зрения разделяет и сам Конфуций, доказательством чего служат такая его известная мысль: «После того, как красота и естественность в человеке уравновесят друг друга, он становится благородным мужем» [Конфуций 2001, 43]. Только в период династии Хань слово «текст» получило общепринятую интерпретацию как письменная форма языка [王凯符 1983,1 ]. Последний вариант интерпретации приближен к современному пониманию текста как самостоятельного письменного произведения, способного передать некое завершенное содержание. 
«Дао» представляет собой более сложное и размытое понятие по сравнению с понятием «текст», однако это не сказывается негативно на его значимости для наук Древнего Китая. В первом словаре китайских иероглифов «Шовэнь цзецзы» слово «Дао» обозначает путь, дорогу, однако содержание данного понятия значительно шире этого толкования. Древнекитайский философ Лао-цзы в своем трактате «Дао дэ цзин» изложил учение о «Дао» и соотношении «Дао» с природой. Согласно учению Лао-цзы, «Дао» является самостоятельной, неизменной и универсальной нормой всего космоса [刘介 民 2004, 32]. С этого момента понятие «Дао» постепенно становится, с одной стороны, широко охватывающим и всеобъемлющим, а с другой стороны, абстрактным и неопределенным. Такой парадокс обуславливается нехваткой доступных понятий для детального анализа сложных вопросов в древние времена, это отметил сам Лао-цзы, написав: «Не зная названия данной нормы, я назвал ее словом Дао». Уже в период правления династии Цзин абстрактное и размытое понятие «Дао» нашло четкую и адекватную интерпретацию у Чжан Сюэчэна. В своей книге «Вэнь ши тун и - Юань дао» он отметил, что «Дао» представляет собой не само бытие всего существующего, а причину бытия всего существующего. «Дао» ничего не делает, и остается естественным. Отметим, что в данном высказывании понятие «Дао» рассматривается, как неизбежный фактор развития и норма для всего существующего в окружающем мире, и оно не может существовать самостоятельно вне реальных вещей. Чжан Сюэчэн также признал неопределенность и абстрактность понятия «Дао» и предложил конкретизировать его с помощью морали, теории, наименования, числа, слова и текста.

Подводя итоги краткого обзора двух ключевых понятий - «текст» и «Дао», отметим, что их понимание и интерпретация подверглись грандиозным трансформациям по мере исторического развития. В соответствии с общепринятым в современном научном сообществе мнением «Дао» является абстрактным и размытым понятием с широким содержанием, а «текст» представляет собой средство конкретизации понятия «Дао». При этом соотношение данных двух понятий не исчерпывается этим определением.

\section{Основные тенденции в соотношении понятий «текст» и «Дао»}

Как изложено выше, вопрос соотношения понятий «текст» и «Дао» берет свое начало в до-Циньскую эпоху. Древнекитайский философ Сюнь-цзы (荀 子, ок. 313-215 гг. до н. э.) выдвинул триединую теорию - почитание «Дао», уважение учения и идей совершенномудрого (то есть Конфуция), высочайший авторитет конфуцианского «Пятикнижия». Сюнь-цзы в своей теории впервые затронул проблему соотношения понятий «текст» и «Дао». По его мнению, выразителем «Дао» является совершенномудрый Конфуций, что письменно зафиксировано в тексте «Пятикнижия» [程福宁 1987, 130]. Таким образом, все, от императора до простого народа, должны учиться у совершенномудрого и почитать классическое «Пятикнижие». Сюнь-цзы заложил фундамент дискуссии о соотношении двух ключевых понятий, и его идея оказала существенное влияние на ряд ученых последующих династий. Ян Сюн в период династии Западная Хань настолько высоко оценивал конфуцианское «Пятикнижие», что доказывал невозможность познания истинного «Дао» без почитания данного текста. Литературный критик Лю Се (刘劦思, 465-532 гг.) в эпоху Южных 
династий еще более развил теорию Сюнь-цзы путем дополнения понятия «Дао» духовными и концептуальными компонентами. В вопросе соотношения «текста» и «Дао» Лю Се следовал за учением Сюнь-цзы и также говорил о необходимости почитания совершенномудрого и классических конфуцианских текстов. И позже, в период правления династии Тан (唐朝, 618-907 гг.), теория Сюнь-цзы осталась актуальной и оказала значительное влияние на идеи Хань Юя (韩愈, 768-824 гг.) (подробно см. ниже). Почитание «Дао», уважение учения и идей Конфуция, а также наивысший авторитет «Пятикнижия» составляли основу характерного для данного периода подхода к пониманию соотношения понятий «текст» и «Дао», - это приверженность конфуцианству как господствующего учения в духовной, литературной и политической сферах.

В эпоху Шести династий (六朝, 229-589 гг.) произошел важный перелом в понимании соотношения понятий «текст» и «Дао», что было обусловлено рядом факторов, среди которых является широкое распространение в IV-VII вв. так называемого парного стиля (пянь вэнь). Данный стиль, возникший в эпоху Вэй-Цзинь и утвердившийся в период Южных и Северных династий (南北朝, 420-589 гг.), представляет собой такой стиль текста, который характеризуется параллельным построением фраз по четыре или шесть иероглифов; лексической, синтаксической и интонационной симметричностью строк; рифмической и ритмической гармоничностью. О характеристиках парного стиля Чжан Шоукан писал следующее: «Будучи стилем с особенно строгими требованиями к внешнему оформлению текста, парный стиль славится изящным оформлением и гармоничным звучанием» [张寿康 1985,35$]$. Однако, вопреки нараставшему интересу к данному красивому стилю в период Южных и Северных династий, критики того времени постепенно заметили и его недостатки - чрезмерно повышенное внимание к формальному аспекту текста неизбежно приводит к относительной пустоте в плане содержания текста, поскольку само содержание текста ограничивается строгим до бессмысленности внешним оформлением. Бессодержательность текста парного стиля, в свою очередь, ускоряет процесс расхождения понятий «текст» и «Дао», так как интерес ко внешней изящности и равнодушие к содержательному ядру лишают функциональное назначение текста как носителя Дао, морали, этикета и долга. В результате этого в эпоху шести династий, с одной стороны, постоянно нарастает стремление к языковой красоте и ритмической гармонии текста, а с другой стороны, ранее центральное понятие «Дао» постепенно уходит из поля зрения образованных людей.

В связи с вышеизложенным положением еще в период процветания парного стиля возникла противоположная тенденция переосмысления соотношения двух понятий. Лю Се в своей выдающейся книге «Литературный дух и резной дракон» (“文心雕龙”, «Вэньсинь дяолун») отметил, что «Дао» зафиксировано в тексте в соответствии с идеями совершенномудрого, а текст функционирует как средство выявления и разъяснения «Дао». Данная идея показывает, что автор идет по пути своих предков Периода Вёсен и Осеней (春秋时代, 770-476/403 гг. до н. э.) и Периода Сражающихся царств (战国时 代, 476/403-221 гг. до н. э.). Лю Се выступает за слияние «текста» и «Дао» и уделяет внимание функциональному аспекту текста. Напомним, что автор интерпретирует «Дао» как основополагающую системы «небо-земля-человек», 
причем центральное место занимает человек. Идею Лю Се развивает Хань Юй, который на основе углубленного понимания ограничений парного стиля и категорического противостояния тенденций в эпоху Южных и Северных династий инициировал Движение по возрождению классической прозы (古文 运动 Гувэнь юньдун) вместе с Лю Цзунъюанем (柳宗元, 773-819) и др. Хань Юй, вслед за своими предшественниками, также выступает за слияние «текста» и «Дао», подчеркивая разъяснительную функцию текста. Следует отметить, что он воспринимает «Дао» в широком смысле слова и включает в него морально-нравственные ценности благородного мужа (君子цзюньизы), что как раз совпадает со стремлением сторонников конфуцианства к совершенной личности. Более того, Хань Юй считает, что высокие моральные качества $а$ втора являются необходимым условием для создания качественного текста и полноценного выполнения его миссии по разъяснению «Дао». Также Хань Юй подчеркивает важность равновесия между функциональным назначением и художественными ценностями текста. Данная идея, с одной стороны, укрепляет позицию слияния понятий «текст» и «Дао», с другой стороны, выдвигает новые критерии для оценки качества текста.

Тенденция слияния понятий «текст» и «Дао» получила дальнейшее укрепление в период династии Сун (宋朝, 960-1279 гг.) по мере возникновения и развития так называемого неоконфуцианства (宋明理学 сунминлисюэ). Напомним, что сторонники неоконфуцианства воспринимают «Дао» в более узком смысле этого слова, что неизбежно приводит к некоторому расхождению между понятиями «текст» и «Дао». Однако в последующем такая тенденция постепенно получила корректировку, и понятия «текст» и «Дао» снова начали приближаться друг к другу.

Особенности соотношения понятий «текст» и «Дао»

Обобщение основных тенденций в соотношении понятий «текст» и «Дао» дает нам возможность анализировать особенности их взаимодействия. Первая и самая главная особенность соотношения двух понятий - это многомерность. Как было нами показано выше, «текст» представляет собой средство конкретизации абстрактного и размытого понятия «Дао», но это лишь один из аспектов соотношения двух понятий. С точки зрения происхождения соотношение понятий «текст» и «Дао» можно сравнить с соотношением истока и течения. Данной точки зрения придерживался и Лю Се, который рассматривал «Дао» как источник триединой системы «небо-земля-человек». Он уверен в том, что «Дао» непосредственно связано с колоритом природы (напомним, что слова «вэнь» и «чжан» обозначают разнообразие цветов), а текст фиксирует и отражает колорит природы, таким образом, понятие «текст» происходит из понятия «Дао». Функциональный подход к рассмотрению соотношения двух понятий приводит к такому выводу, что это аналогично соотношению функционального назначения и выполнения данной функции конкретным предметом, или другими словами, соотношению теории и практики. Согласно данному подходу, «Дао» задает функциональные рамки, наполнение которых осуществляется самим текстом. Отметим, что данный подход соответствует тенденции слияния и равновесия понятий «текст» и «Дао». Действительно, с точки зрения текстоведения соотношение этих двух понятий есть соотношение содержания и выражения языковой единицы. Идея, содержащаяся в конкретном 
тексте, относится к понятию «Дао», а сам текст представляет собой инструмент и средство для воплощения или реализации идеи. Конфуций говорил, что нужно направить свою волю на достижение «Дао», а Сюнь-цзы предложил воплощать волю с помощью текста, создав таким образом цепь «Дао-волятекст». Данная теория оказала существенное влияние на мыслителей и философов последующих династий. Многомерность соотношения понятий «текст» и «Дао» свидетельствует о сложной и междисциплинарной природе данного вопроса и дает возможность для разнообразной интерпретации. Иными словами, многомерность соотношения двух понятий является движущей силой, стимулирующей появление перечисленных выше тенденций.

Следующая особенность соотношения понятий «текст» и «Дао» - это концепция равновесия и гармонии, основания которой были сформированы еще в период зарождения древнекитайской цивилизации. Испокон веков у китайцев культивировалось стремление к равновесию космических сил «инь» и «ян», а также к гармонии субъективной и объективной сторон всего сущего [李斌城 2002, 301]. Концепция равновесия и гармонии оказала огромное влияние на многих древнекитайских мудрецов, в том числе Конфуция, который выступает за «серединное» и «гармоничное» как в личности человека, так и в общественных делах. Что касается взаимодействия понятий «текст» и «Дао», то равновесие проявляется преимущественно в том, что в разные исторические периоды китайские ученые пытаются уделять одинаковое внимание этим двум фундаментальным понятиям. Даже в случае дисбаланса ученые сделали все возможное, чтобы соотношение понятий «текст» и «Дао» вернулось в правильное русло (см. работы Лю Се и Хань Юй). Также гармоничное сочетание этих двух понятий во многом определило и критерии оценки текста.

Еще одна особенность - это этикоцентристское понимание соотношения понятий «текст» и «Дао», что во многом было предопределено социальноэкономическими условиями натурального хозяйства и традиционного патриархального уклада [葛晓音 2011,73 ]. Конфуцианская этика нацелена на формирование специфической формы государства-семьи и утверждения моральнонравственных ценностей личности в виде благородного мужа. Этот подход, безусловно, содействовал сближению и даже слиянию понятий «текст» и «Дао», о чем свидетельствует триединая теория Сюнь-цзы - почтение «Дао», уважение к идеям и учениям совершенномудрого Конфуция и абсолютный авторитет «Пятикнижия». Однако погружение в учение классиков и мысли предков замедлило развитие конфуцианства в целом и теории о соотношении понятий «текст» и «Дао» в частности. Кроме того, чрезмерное увлечение идеями прошлого привело к отклонению теории от практики, что негативно сказалось не только на качестве создаваемых текстов, но и на развитии общественной и научной жизни.

\section{Влияние на развитие древнекитайского текстоведения}

Текстоведение представляет собой комплексную науку, изучающую правила внутренней текстовой организации, а также закономерностей написания и чтения текста [杨振道 1984,1$]$. Текстоведение следует отличать от текстологии, отрасли филологии, изучающей произведения письменности, литературы и фольклора в целях критической проверки, установления и организации их текстов для дальнейшего исследования, интерпретации и публикации. 
Объектом же исследования текстоведения является письменный текст во всех функциональных стилях. Предметом текстоведческого исследования является изучение возникновения и развития текста, создание классификаций текста, определение структурных компонентов текста и их взаимодействия, поиск закономерностей написания и чтения текста, определение критериев оценки качества текста, характеристика стиля и анализ индивидуальности автора в тексте и др. [Чжао Чжунган 2019, 170]. История развития текстоведения началась во времена династии Восточной Хань (東漢, 25 - 220 гг.), а период процветания текстоведческих исследований наступил в период династии Северной Сун (北宋, 960-1127 гг.) по мере нарастающего многообразия жанров и стилей текста. Отметим, что на раннем этапе своего развития текстоведение частично совпадает с теорией литературы, но в ходе исторического развития эти две науки постепенно отклоняются друг от друга, в результате чего текстоведы уделяют особое внимание онтологическим особенностям текста, а литературоведы фокусируются на связях между литературным произведением и множеством явлений вне текста.

Как изложено выше, дискуссия о соотношении понятий «текст» и «Дао» оказала существенное влияние на разные области науки и общественной жизни. Одним из самых ярких проявлений такого влияния является трансформация теории древнекитайского текстоведения. Сама история текстоведения берет свое начало во II в., но предпосылки становления данной научной дисциплины появились намного раньше. В то время не было стройной теоретической системы об онтологических закономерностях текста, присутствовали только отдельные идеи, разбросанные в трудах о литературе, философии, политике у разных ученых данного периода. Естественно, это было обусловлено отсутствием детальной классификации научных дисциплин и непонимание учеными того времени внутренних связей между различными теоретическими фрагментами. Сюнь-цзы первым сформулировал разъяснительную функцию «текста» во взаимодействии с «Дао» и связал эти два ключевых понятия с конфуцианством. В дальнейшем его работа вдохновила других ученых систематизировать и объединять в общую теорию различные идеи о тексте, что и привело к появлению текстоведения.

Изменения, которые произошли в определении соотношения понятий «текст» и «Дао», стимулировали жанровую реформу текста и расширили саму проблематику понимания текста. Проза династий Чжоу, Цинь и Хань характеризуется разнообразием синтаксических конструкций и отсутствием стройной гармоничной рифмы. С появлением парного стиля в эпоху Вэй-Цзинь внимание было приковано к формальному построению и благозвучию текста. Усилия Хань Юя и Лю Цзунъюаня по возрождению классической прозы еще раз изменили путь развития текстовых жанров. Очевидно, что каждый такой поворот в развитии текстовых жанров сопровождался появлением новой тенденции в вопросе соотношения между понятиями «текст» и «Дао». Другим важным аспектом является изменение проблематики текста в разные исторические периоды. Так, вплоть до династии Цинь содержание текста было тесно связано с идеями и учениями конфуцианства, а на проблематику текста влияло стремление к воплощению в жизнь великого «Дао» и к личному достижению морально-нравственных стандартов благородного мужа (изюньизы). 
Но в период Южных и Северных династий центральное место в процессе написания текста занимает формальная красота и благозвучие, а содержание текста теряет связь с актуальной проблематикой в политической, культурной и общественной сферах. Со времен династии Тан содержание текста снова занимает ключевое место, и авторы уделяют внимание не только идеалам конфуцианства, но и вопросам общественной жизни, духовному миру человека и многому другому, в результате чего значительно расширяется и обогащается проблематика текста того времени.

\section{Выводы}

На основе диахронического анализа соотношения понятий «текст» и «Дао» мы пришли к выводу, что понятия «текст» и «Дао» воспринимаются и интерпретируются в зависимости от ряда социально-экономических, политических и культурных факторов в конкретно-исторических условиях. Соотношение между этими двумя понятиями менялось в ходе исторического развития, и данные изменения нашли свое выражение в различных отраслях науки, в том числе и в текстоведении. Процесс становления текстоведения как самостоятельной научной дисциплины и усовершенствование ее теоретической системы существенно ускорилось благодаря непрерывной дискуссии о соотношении понятий «текст» и «Дао». Данная дискуссия также оказала влияние на формирование жанрового многообразия и проблематику текста в разные исторические периоды. Необходимо особо отметить, что хотя текстоведение было нацелено на изучение древних текстов, однако эта отрасль знаний остается актуальной и для современной науки, что, прежде всего, касается лингвистики текста, литературоведения, философии и др.

\section{ЛИТЕРАТУРА}

程福宁。文章学基础。长沙: 湖南大学出版社, 1987。326页。

葛晓音。唐宋散文。上海: 上海古籍出版社, 2011。159页。

李斌城。唐代文化。北京: 中国社会科学出版社, 2002。615页。

刘介民。中国比较诗学。广州: 广东高等教育出版社, 2004。439页。

任遂虎。文章学通论。北京: 清华大学出版社, 2011。376页。

王凯符。古代文章学概论。武汉: 武汉大学出版社, 1983。241页。

杨振道。文章学概论。武汉: 武汉大学出版社, 1984。391页。

张寿康。文章学导论。武汉: 湖北教育出版社, 1985。198页。

Конфуций. Лунь Юй (Беседы и суждения). Москва : «Восточная литератуpa», 2001. $180 \mathrm{c}$.

Чжао Чжунган. Основные идеи китайского текстоведения и возможность их применения в лингвистическом изучении текста. Вестник ПВГУС. 2019. № 5. C. 170-174.

\section{REFERENCES}

Cheng Funing (1987), Wenzhang xue jichu, Hunan daxue chubanshe, Zhangsha. (In Chinese).

Ge Xiaoyin (2011), Tang song sanwen, Shanghai guji chubanshe, Shanghai. (In Chinese).

Li Bincheng (2002), Tang dai wenhua, Zhongguo shehui kexue chubanshe, Beijing. (In Chinese). 
Liu Jiemin (2004), Zhongguo bijiao shi xue, Guangdong gaodeng jiaoyu chubanshe, Guangzhou. (In Chinese).

Ren Suihu (2011), Wenzhang xue tonglun, Qinghua daxue chuban she, Beijing. (In Chinese).

Wang Kaifu (1983), Gudai wenzhang xue gailun, Wuhan daxue chuban she, Wuhan. (In Chinese).

Yang Zhendao (1984), Wenzhang xue gailun, Wuhan daxue chubanshe, Wuhan. (In Chinese).

Zhang Shoukang (1985), Wenzhang xue daolun, Hubei jiaoyu chuban she, Wuhan. (In Chinese).

Konfutsiy (2001), Lun' Yuy (Besedy i suzhdeniya), "Vostochnaya literature", Moskva. (In Russian).

Chzhao Chzhungan (2019), "Osnovnye idei kitajskogo tekstovedeniya i vozmozhnost' ih primeneniya v lingvisticheskom izuchenii teksta", Vestnik PVGUS, No. 5, S. 170-174. (In Russian). 